DIGITALCOMMONS

-@WAYNESTATE-
Michigan Journal of Counseling:

Research, Theory and Practice

Volume $30 \mid$ Issue 1

Article 2

$2-1-2002$

\title{
Pedagogical Strategies In Multicultural Counseling: Developing coherent assignments to promote competency
}

Devika Dibya Choudhuri

Eastern Michigan University, dibya@yahoo.com

Suzanne M. Hobson

Eastern Michigan University

Follow this and additional works at: https://digitalcommons.wayne.edu/mijoc

\section{Recommended Citation}

Choudhuri, D., \& Hobson, S. M. (2002). Pedagogical Strategies In Multicultural Counseling: Developing coherent assignments to promote competency, Dimensions of Counseling, 30(1), 1-9. doi: 10.22237/mijoc/1012521660

This Article is brought to you for free and open access by the Open Access Journals at DigitalCommons@WayneState. It has been accepted for inclusion in Michigan Journal of Counseling: Research, Theory and Practice by an authorized editor of DigitalCommons@WayneState. 


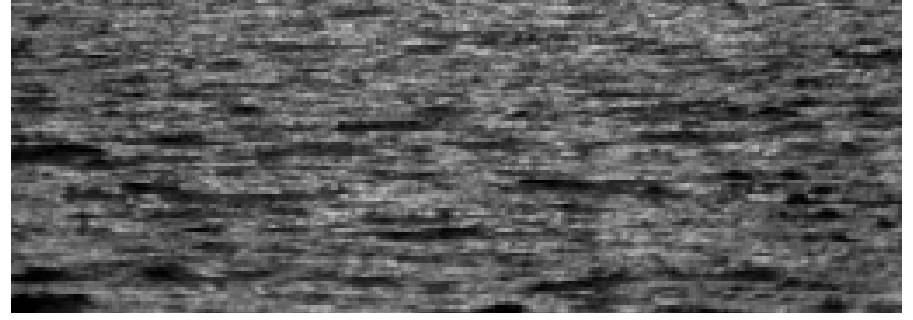

\section{Pedagogical Strategies In Multicultural Counseling} Developing coherent assignments to promote competency

\section{Devika Dibya Choudhuri, Ph.D.} Suzanne M. Hobson, Ed.D.

Eastern Michigan University

\author{
Dibya Choudhuri is an Assistant Professor in the Department of \\ Leadership and Counseling at Eastern Michigan University, \\ Ypsilanti, MI 48197. Her email address is dibya@yahoo.com
}

\begin{abstract}
This article describes a set of assignments developed by
the lead author that form the foundation of an
introductory graduate course in multicultural
counseling. This set of assignments draws on the vast
research available on pedagogical approaches to teaching
multicultural counseling and is explicitly linked to the
knowledge-based multicultural counseling competencies
(Arredondo et al., 1996). The overall philosophy,
individual assignment objectives, student responses, and
class context are described.
This article describes a set of assignments developed by
the lead author that form the foundation of an
introductory graduate course in multicultural
counseling. This set of assignments draws on the vast
research available on pedagogical approaches to teaching
multicultural counseling and is explicitly linked to the
knowledge-based multicultural counseling competencies
(Arredondo et al., 1996). The overall philosophy,
individual assignment objectives, student responses, and
class context are described.

This article describes a set of assignments developed by
the lead author that form the foundation of an
introductory graduate course in multicultural
counseling. This set of assignments draws on the vast
research available on pedagogical approaches to teaching
multicultural counseling and is explicitly linked to the
knowledge-based multicultural counseling competencies
(Arredondo et al., 1996). The overall philosophy,
individual assignment objectives, student responses, and
class context are described.

This article describes a set of assignments developed by
the lead author that form the foundation of an
introductory graduate course in multicultural
counseling. This set of assignments draws on the vast
research available on pedagogical approaches to teaching
multicultural counseling and is explicitly linked to the
knowledge-based multicultural counseling competencies
(Arredondo et al., 1996). The overall philosophy,
individual assignment objectives, student responses, and
class context are described.

This article describes a set of assignments developed by
the lead author that form the foundation of an
introductory graduate course in multicultural
counseling. This set of assignments draws on the vast
research available on pedagogical approaches to teaching
multicultural counseling and is explicitly linked to the
knowledge-based multicultural counseling competencies
(Arredondo et al., 1996). The overall philosophy,
individual assignment objectives, student responses, and
class context are described.

This article describes a set of assignments developed by
the lead author that form the foundation of an
introductory graduate course in multicultural
counseling. This set of assignments draws on the vast
research available on pedagogical approaches to teaching
multicultural counseling and is explicitly linked to the
knowledge-based multicultural counseling competencies
(Arredondo et al., 1996). The overall philosophy,
individual assignment objectives, student responses, and
class context are described.

This article describes a set of assignments developed by
the lead author that form the foundation of an
introductory graduate course in multicultural
counseling. This set of assignments draws on the vast
research available on pedagogical approaches to teaching
multicultural counseling and is explicitly linked to the
knowledge-based multicultural counseling competencies
(Arredondo et al., 1996). The overall philosophy,
individual assignment objectives, student responses, and
class context are described.

This article describes a set of assignments developed by
the lead author that form the foundation of an
introductory graduate course in multicultural
counseling. This set of assignments draws on the vast
research available on pedagogical approaches to teaching
multicultural counseling and is explicitly linked to the
knowledge-based multicultural counseling competencies
(Arredondo et al., 1996). The overall philosophy,
individual assignment objectives, student responses, and
class context are described.

This article describes a set of assignments developed by
the lead author that form the foundation of an
introductory graduate course in multicultural
counseling. This set of assignments draws on the vast
research available on pedagogical approaches to teaching
multicultural counseling and is explicitly linked to the
knowledge-based multicultural counseling competencies
(Arredondo et al., 1996). The overall philosophy,
individual assignment objectives, student responses, and
class context are described.

This article describes a set of assignments developed by
the lead author that form the foundation of an
introductory graduate course in multicultural
counseling. This set of assignments draws on the vast
research available on pedagogical approaches to teaching
multicultural counseling and is explicitly linked to the
knowledge-based multicultural counseling competencies
(Arredondo et al., 1996). The overall philosophy,
individual assignment objectives, student responses, and
class context are described.
\end{abstract}

s the counseling profession has continued to embrace
the importance of providing culturally competent
services to a diverse clientele, counselor education programs across the state of Michigan and indeed across the nation have responded with an increased focus on teaching multicultural counseling competencies. Although the development of multicultural counseling competence in graduate students is ideally achieved through the infusion of this content throughout the counseling curriculum, the ability and/or willingness of counselor education programs to accomplish such infusion varies widely. More commonly, the bulk of the responsibility for helping students develop multicultural counseling competence falls to the instructor(s) responsible for teaching an introductory or core course specifically focused on multicultural competence.

This article addresses the pedagogical issues involved in teaching such an introductory course on multicultural counseling. Specifically, it discusses pedagogical issues as they relate to multicultural training and then provides a 
set of assignments that is directly linked to the research base on multicultural counseling. While the assignments described here are not individually unique, their focus on explicitly linking the combination of assignments and the teaching process to a pedagogical stance is unique.

\section{Pedagogical Issues in Multicultural Counselor Education}

The teaching of multicultural counseling is a complex endeavor, requiring the instructor to balance (a) helping students identify and discard existing attitudes, knowledge and skills that are untrue or unhelpful with (b) helping students acquire new knowledge, attitudes and skills that will be more accurate and helpful in providing culturally competent services to diverse clients. Adding to the complexity of teaching multicultural counseling is the instructor's dual responsibilities to attend to both the needs of the students and to the future welfare of clients that the students will eventually counsel. Finally, the teaching of multicultural counseling requires that the instructor not only be adept in the practice of multicultural counseling but also be well-versed in pedagogical issues related to helping others develop competence in this area.

Fortunately, the field of counselor education has given great attention to pedagogical issues related to the area of multicultural counseling training (e.g., Kiselica, 1998; Pedersen, 1994; Sue, Akutsu, \& Higashi, 1985; Sue \& Sue, 1990).

\section{Dimensions of Multicultural Counseling Competence}

In a significant contribution, Sue et al. (1982) delineated three major dimensions of competency in multicultural counseling: awareness, knowledge, and skill. In Sue et al. (1998), these dimensions were expanded and described in greater detail. Most measures of multicultural counseling competencies (e.g. Ponterotto et al., 1994, Sodowsky, 1996) as well as guidelines (Sue, Arredondo, \& McDavis, 1992) use this basic framework.

Although these dimensions of multicultural counseling competence are accepted and well-recognized, counselor education programs must ensure that they address all three dimensions sufficiently. Pedersen (1994) identified that a common flaw in multicultural training is an overemphasis on any one dimension to the detriment of the others. For example, an overemphasis on the awareness dimension may well guide students to becoming aware of their own shortcomings as well as environmental inadequacies. However, it does not equip them with the knowledge and skills necessary to effectively advocate for their clients. Similarly, emphasizing knowledge with huge doses of data fails to convince students of the legitimacy or importance of applying the information in counseling (awareness) or provide them with the skills to do so.

In striving to address each dimension sufficiently, counselor education programs must also recognize that courses in multicultural counseling cannot sufficiently address the skills dimension unless they are based in a practicum experience. The introductory/core courses commonly included in master's degree programs are much more effective at enhancing student awareness and knowledge of multicultural issues rather than for introducing students to specific skills or interventions useful in multicultural counseling. Such a course can thereby provide a foundation for additional skill development in practicum experiences.

\section{Operationalization of Multicultural Counseling Competencies}

Arredondo et al. (1996) conducted further research on developing multicultural counseling competence in students. Specifically, Arredondo et al. (1996) provided the following operationalization of these three dimensions of counseling competence into measurable objectives. This operationalization is crucial to counselor education programs wishing to develop and assess multicultural competence in their students.

\section{Awareness: Counselor-Centered Competencies}

With respect to the awareness dimension, counselor education programs should focus on the development of counselor-centered competencies. These counselorcentered competencies involve helping students develop self-awareness; promoting students' increasing understanding of their own personal histories and worldview; and assisting students in achieving insights into their biases, relationships, and stances toward themselves and others.

\section{Knowledge: Client-Centered Competencies}

With respect to the knowledge dimension, counselor education programs should focus on the development of client-centered competencies. These client-centered competencies involve helping students develop knowledge about the social groups to which the client belongs; assisting students in understanding the 
influence of a client's life experiences, cultural heritage, and historical background; and in familiarizing students with relevant identity development models and culturally appropriate counseling interventions.

\section{Skills: Institutional/Societal Based Competencies.}

With respect to the skills dimension, counselor education programs should focus on the development of institutional/societal based competencies. These institutional/societal based competencies involve helping students gain knowledge of the sociopolitical influences that impact the lives of racial and ethnic minorities (such as an understanding of the cycle of oppression, immigration and its psychosocial consequences); developing an understanding of social privilege; promoting awareness of the ways in which commonly used models and theories of counseling and assessment have been culturally encapsulated and often discriminatory; and learning about ways to combat institutional obstacles to client well-being.

These pedagogical issues provide counselor education programs with significant guidance in developing an approach to the training of multiculturally competent counselors. Course content, teaching methodology and assignments can be developed in consideration of these pedagogical issues. The remainder of this article focuses on a specific set of assignments designed by the lead author for use in an introductory / core course on multicultural counseling. These assignments are directly linked to the dimensions of multicultural competence identified and described by Sue et al. (1985) and Sue et al. (1992) and to the operationalization of these dimensions provided by Arredondo et al. (1996).

\section{Pedagogically Based Assignments}

Over the course of the semester, the students in the lead author's class had a set of three assignments to complete in sequential order: (1) an autobiographical paper of selfin-context; (2) a qualitative cultural interview; and (3) an annotated resource bibliography. These assignments were complemented by an on-going reflection journal and a final examination in the form of a counseling case study. To enhance student ability to complete these assignments with integrity and competence, it was also important to support these assignments with a structured set of readings and with content-based discussions in class. In the following sections, each of these assignments is described in detail. The descriptions include an overview of the assignment's content, its objectives, the class context that supported the assignment, and common student responses to the assignment.

\section{Autobiographical Paper}

Overview. In this paper, students were asked to explore and articulate their own cultural and socio-economic class background, including values, beliefs, customs, traditions, and history. A cultural genogram (Hardy \& Laszloffy, 1995) was part of this paper, as family-of-origin was considered crucial to exploring the beliefs and norms with which they were raised. In writing this paper, students were encouraged to utilize knowledge gathered from parents, friends and relatives as well as textual sources such as photographs and scrapbooks. In analyzing the information they gathered, students were asked to consider how race/ethnicity, gender, social class, and family values had influenced their development. They were also asked to pinpoint what they believed to be their place in the identity development models consistent with their racial/ ethnic group membership whether it be Korean American (Kim, 1981), White (Helms, 1990), African American (Cross, 1991) or Latino (Ruiz, 1990). [Sue et al. (1998) provide an exhaustive overview and listing of the major identity development models.] Although the paper was the first assignment to be submitted, the instructor provided students with feedback and not a grade. Students were then encouraged to rework the paper in light of new learning and insight as they continued through the course.

Objectives. The purpose of the autobiographical paper was to focus the students' attention on self, locating themselves as cultural beings with frames of meaning that constructed their stances toward others. The paper met the first requirement of the counselor-centered competency of specific knowledge about their own racial/ethnic heritage and how it might affect and impact their worldview (Arredondo et al, 1996). According to Sodowsky, Kuo-Jackson, and Loya (1997), cultural selfexploration encourages awareness of a collective-self that is immensely valuable in understanding the processes inherent in a multicultural counseling relationship. Metaphorically speaking, until students begin to explore the ground they stand on, it is unlikely that they will be able to construct much of a stable bridge to meet a cultural Other. Allowing the paper to be a work-inprogress was explicitly linked to the notion of selfexploration as a continuing journey.

Class Context. To support this first assignment of selfexploration, the beginning part of the course focused on awareness-building exercises that encouraged insight into self and cultural value systems. It was also important to provide frameworks and models of similar explorations that allowed students to understand the emotional and often painful aspects of soul-searching. For instance, an essay by McIntosh (1988) articulated invisible privileges 
in terms of both racism and sexism. Similarly, Bulkin (1984) described, with searing honesty, a personal journey into her complex social identities involving both privilege and oppression as a White, middle class, Jewish lesbian. Both sets of readings often evoked emotional reactions from students that, if processed carefully, led to deeper selfexploration. To accommodate different learning styles as well as to offer different perspectives, various films were also used as teaching aids. Films can enhance empathic understanding of issues in ways that texts may be unable to do and there are many lists of such films (Pinterits and Atkinson, 1998). Films such as The Color of Fear (Wah, 1994) or Black is...Black ain't (Riggs, 1996) are both disconcerting as well as enlightening because they contain powerful emotional content and complex characterizations that belie stereotypes [Appendix I provides a partial list of such films]. Additionally, theories of identity development (e.g. Atkinson, Morten \& Sue, 1983; Helms, 1990; Kim, 1981; Ponterotto, 1988) need to be presented and processed in the context of helping students apply the models to themselves.

Student Responses. European American students often began the course by identifying themselves as acultural and by expressing a lack of awareness of their cultural history and identity. Such students frequently reported that this exercise widened their perspective, allowing them to see how they did indeed have a racial, ethnic, and cultural heritage. In the journals, these students often commented that the paper was one of the hardest pieces of work they had done in their program because they realized how much they didn't know about themselves. For many, this assignment initiated a process of discovering more about the silences and unspoken histories of privilege and oppression that were a part of their heritage. For instance, in the course of working on this paper, a Jewish-American student of Eastern European heritage allowed herself to claim her silenced Jewish identity through conversations with grandparents who had been estranged.

For students of African, Latino, Asian, and Indigenous heritage, this paper provided an opportunity to define a self-identity that was not simply reactive to societal definitions. Often, such students had explicitly or implicitly framed themselves in acceptable categories, denying aspects that overflowed. For instance, a biracial student who was both African American and Native American had denied her indigenous heritage in selflabeling because of messages from both the dominant society as well as the African American community. These messages, although coming from different sources, resulted in her belief that she should only identify as Black. The autobiographical paper provided this student with an opportunity to explore the ways in which her indigenous heritage had framed many of her belief systems about helping, healing, and the role of community. Overall, for both majority and minority students, the process of self-scrutiny served the function of enhancing the goal of multicultural awareness and set the stage for the next assignment.

\section{Qualitative Cultural Interview}

Overview. In this assignment, students were directed to seek out a member of an ethnic/ cultural group different from their own and to conduct a qualitative, in-depth interview with this person. They were encouraged to refer to The Person-inCulture Interview (Berg-Cross \& Zopetti, 1991) for particular topics to focus on, but they were also required to frame specific questions based on the process of the interview itself.

In selecting a person to interview, students were instructed that their choice should be dictated by thinking about possible clients from this group in their future professional life. Further, students were required to discuss their choice with the instructor. For instance, a European American school counselor-in-training who planned to work in a rural setting that had a large population of Native Americans was encouraged to choose to interview someone who was Native American.

When preparing for the interviews, students were also cautioned that while the interviews were opportunities to develop rapport and practice counseling skills of accurate listening, they were not to be counseling sessions. Once the interview was completed, students discussed their findings in small groups in class and received feedback from their peers. In some cases, this discussion resulted in a student choosing to conduct a follow-up interview as well as to do additional reading on the interviewee group's sociopolitical history. The students then wrote and submitted a paper that described the interview and themes that emerged, and that explored their own reflections and learning.

Objectives. The Qualitative Cultural Interview assignment addressed the client-centered competencies (Arredondo et al, 1996). In effect, students were now asking another person the kinds of questions they had been asking themselves in the previous assignment. 
Having this assignment follow the autobiographical selfexploration increased student sensitivity to the potential difficulty and emotional risk of particular questions in terms of their impact on the interviewee. This assignment also provided students with the opportunity to be in intimate contact with a person they would not ordinarily seek out. The fact that it was a class assignment propelled such students into initiating contact that they might otherwise fear and the experience often dispelled stereotypes the students may have held. Fear and anxiety about this cross-cultural meeting as well as that of "making a mistake" could be experienced and processed by students in a relatively safe way. When carried out successfully, the assignment thereby enabled students to reduce their anxiety about future encounters with culturally different persons.

In addition, having students discuss the interview and the experience of it in small groups of peers served several functions. First, it allowed the students to identify reactions to both the content and process of the interview and to begin thinking more clearly about the emerging themes as well as their own reactions. Second, other students who had interviewed a different member of the same group added insight with their differential experience, disallowing blanket generalizations. Third, the process was somewhat like peer supervision, encouraging students to process multicultural issues with the same candor with which they are encouraged to process other clinical issues.

Class Context. While students were working on the course assignment of the Qualitative Cultural Interview, it was helpful to use class meetings to cover specific cultural information about various ethnic groups. The course content during this time focused primarily on the four major ethnic groups (African Americans, Latino/a Americans, Asian American and Pacific Islanders, and Native Americans) that have been specifically targeted in this society by racism. Reynolds (1995) identified the importance of providing culturally specific information so that individuals understand that differences do exist on group levels. To prevent such information from fostering rigidity and stereotyping, though, Ridley, Espelage and Rubinstein (1997) encouraged the use of cautions to apply information as guidelines rather than rules in counseling. Normative group information can then be used as hypotheses to be validated specifically and contextually in the course of counseling. Having specific normative information about the group whose member the student was going to interview framed the context of the interview, while informing and sensitizing the student to be alert to noticing confirmations or contradictions of such information in the interview.

Another in-class activity designed to support this assignment involved conducting practice interview sessions in class. This strategy was helpful in assisting students to prepare for the interview, to identify effective communication strategies for the interview (reducing the likelihood of insensitive questioning), and to reduce students' anxiety about the interview. One technique was to have students in the class role-play an interview to generate opening questions. Such a strategy can be problematic if the class is not ethnically diverse, though, because of the additional burden on students from ethnic minority groups to be unpaid teachers. In such situations, it was helpful to invite colleagues and counselors who are members of racial/ethnic minority groups to serve as informed and expert volunteer role-players.

Student Responses. Often, the learning from this assignment would begin when European American students realized that they knew no one from a particular racial/ ethnic group with whom they were going to be working. One European American woman who had earlier described herself as "treating everyone the same without regard to color" acknowledged that in her personal, work, and social settings, she had had so little contact with any ethnic minorities that she could not find anyone to interview. In journals, European American students tended write of their surprise both at the commonalties they found as well as profound differences in perspective and experience.

This assignment was constructed somewhat differently for students who were from ethnic minority backgrounds in that it was not as simple as interviewing someone from a ethnic group different from their own. Some students wanted to interview a European American, but unless they came from a background of little contact with European Americans, this was rarely allowed. Instead they were encouraged to interview a member of a different ethnic minority group of whom they knew little. For many African American and Latino students, the enigmatic group of choice to be interviewed was Asian Americans. Sometimes, students who had been adopted, had biracial heritage, or had a heritage that was denied, chose to interview someone who was from their "own" group (a group to which they did not feel a sense of belonging regardless of societal identification). For instance, a third-generation Chinese American man who had been raised in completely European American environments, found that it felt most challenging and informative to interview a Chinese-born American.

One of the key discoveries that was processed in the class discussions of this assignment was that the interviewee's discomfort was fed by the student's own anxiety. As students shared with each other how the interview "warmed up" as they themselves began to relax about making mistakes, students were faced with the interactive nature of the relationship and its implications for counseling. Many students reported coming out of the 
interview thinking about the interviewee's responses as informative only about the interviewee. After the in-class discussions highlighted the different interview experiences and the changes being initiated by the interviewer, many were shocked at how much their own stance had influenced both the course of the interview as well as the information gained.

\section{Annotated Resource Bibliography}

Overview. In the third assignment, students were asked to collect a bibliographic list of resources that focused on a specific group. For purposes of developing specific competency, it was recommended that they pick a group whose member they interviewed. This set of resources was designed to be of help in counseling members of such a group. Students were directed to include scholarly articles and books on issues such as cultural values, sociopolitical history, counseling interventions, research and assessment. In addition, students were asked to find multimedia resources such as art, music, film, and literature. In other words, the resource list addressed both the theory as well as the lived experience of members of the group. Each item on the list was to be annotated with a brief description.

Objectives. This assignment encouraged students to begin to address the third set of institutional/societal based competencies (Arredondo et al, 1996). Developing the bibliography introduced them to the wealth of resources available on multicultural counseling. Citing a deficit in knowledge as an excuse for multicultural incompetence became an invalid argument as students began to realize that only their own resistance was the barrier. Completing the bibliography also added empirical understanding to themes they may have noted during their qualitative cultural interview.

There was an added dimension to this assignment in that students were asked to submit the bibliography before the end of class. With their permission, the bibliographies were then duplicated and each student received a collated set of annotated bibliographies to begin their own library of resources dealing with multicultural issues. This aspect of the assignment was explicitly framed as consultation and moved the solitary and individualistic task of learning to a group-based effort. The efforts of the individual added to the resources of the group, with no individual being required to know everything about every cultural group. This was often a helpful realization at a stage when students were likely to be overwhelmed by how much they had not known and to feel close to giving up.
Class Context. While students were developing the final set of annotated bibliographic resources, it was helpful to structure class content and reading on culturally specific counseling skills and interventions, as well as on the contexts of other areas of identity that may impact the multicultural counseling relationship. At this point, addressing significant issues of gender, class, sexual orientation, age, and disability was necessary to demonstrate the complexity of identity and to prevent retreat into stereotypical responses. For instance, understanding how gender, class and sexual orientation could frame the contexts in which a working-class African American gay man experienced his reality, discouraged students from applying formulaic thinking to the range of issues facing African Americans.

Student Responses. Having experienced the Qualitative Cultural Interview prior to this assignment, students were often far more receptive to the challenges of applying culture-centered interventions as well as eager to learn about the nuances of their effective use. For many students, this assignment seemed to be crucial turning point that moved them toward a feeling a sense of beginning competency about multicultural issues. In their journals and class discussions, they often expressed an "Aha" feeling as they began discovering the resources available. Often they found resources that addressed the particular questions they had and felt both supported and challenged to explore further on their own. For instance, a student who had been feeling anxious and overwhelmed about the prospect of facilitating an African American girls group in her school setting found many resources on that specific issue. She described herself as now being far more ready to place herself in situations where she would be working with children of color. European American students who had had previous experiences at counseling sites often also reported a sense of anger and feeling of having been cheated. In their journals, they described themselves as having been kept unaware and expressed a wish that they had known that these resources were available when working at their previous site. Students of ethnic minority heritages sometimes reported experiencing a sense of awe and delighted recognition of themselves as being present in the literature. One Chicano man described it as "never knowing there was so much research out there on people like me."

\section{Effectiveness of Assignments}

The lead author of this article developed these assignments in an attempt to directly link them and the course to pedagogical issues related to multicultural counseling as articulated by Sue et al. (1982), Sue et al. (1998), and Arrendondo et al. (1996). She then utilized this set of assignments in the context of an introductory / core course on multicultural counseling for two semesters. In assessing the effectiveness of these 
assignments, the lead author relied on formal, anonymous end-of-course student evaluations, on informal feedback offered by students during class discussions or in journal entries, and on her observation of student growth as evidenced in their assignments and their in-class discussions.

The qualitative feedback offered in journal entries and informal course evaluations indicates that students perceive themselves to be changed by their experience. In anonymous course evaluations, students overwhelmingly rated the assignments as being good to excellent in their value in enhancing understanding of multicultural issues and meeting the objectives of the course. They also rated the lead author's instructional style as non-threatening yet challenging, and they perceived her facilitation of the class discussions as having contributed to their learning.

Students from this course have sometimes come back after their internship experience to speak about the ways in which they purposefully constructed experiences on their counseling site that would enhance their multicultural counseling skills. For instance, one European-American student in a relatively mono-cultural high school site, made connections with a local community agency and ended up co-facilitating a 'teens of color' support group with an experienced group leader. Another student, who was a Taiwanese international student, sought out an internship in a school located on the neighboring Native American reservation. Overall, students described the course in positive terms and declared they had a better understanding of the complexity of issues as well as a realization that they had much more to learn.

\section{Discussion}

\section{Benefits of this Strategy}

The development of course assignments directly linked to pedagogical methods specific to multicultural counselor education appears effective in promoting student growth. It also supports the teaching process by identifying specific student outcomes (awareness, knowledge and skill) as goals. Having such explicit goals helps to structure the course in two important ways. First, identifying these broad goals of the course for the students enables to better understand the purpose of the course and to take ownership over their own progress toward these goals. Second, it provides instructors with a way to organize some of the vast material that is available. Without such an organizational structure, the instructor is often understandably overwhelmed with the myriad issues with which multicultural counseling is concerned.

\section{Possible Limitations of this Strategy}

Although preliminary findings would suggest that this pedagogical strategy for teaching multicultural counseling contributes positively toward student growth, on limitation is that no assessment has been conducted to determine the longterm effects of such a course structure.

Therefore, conclusions about the effectiveness of this pedagogical strategy are not yet possible and additional research is warranted. According to a national survey by Holcomb-McCoy and Myers (1999), taking a multicultural counseling course positively influences the self-perceived multicultural knowledge and racial identity competence of counselors in that such counselors rate themselves more highly. It is uncertain, however, whether clients who encounter counselors who went through such training experience a profound difference and receive more effective counseling. It is possible that students who go through such a course may end up erroneously perceiving themselves to be multiculturally competent when they actually have much more to learn. Well-intentioned and relatively naive, they may end up doing more damage in working with diverse clients due to a misguided sense of competence.

On the other hand, being sensitized to the issue and being able to bring up issues of culture may have a positive impact on counseling. Thompson, Worthington and Atkinson (1994) investigated the effect of counselors' addressing the client's culture in counseling on African American women clients. They found a significant positive relationship between the counselor's addressing of culture with the client's depth of self-disclosure.

Another limitation of this pedagogical strategy is that it focuses solely on the introductory/core course in multicultural counseling. In terms of overall training, it would obviously be more advantageous to have the entire counselor education curriculum infused with multicultural counseling competencies or, at a minimum, have a practicum experience dedicated to cultural competence. Otherwise, instructors for the introductory / core course in multicultural counseling face the impossible directive of instilling multicultural counseling competency in the course of sixteen weeks and students face the similarly impossible task of accomplishing the 
attitudinal, awareness, knowledge and skill development necessary for multicultural competence in a single semester. One course, however it is designed, suffers from the limitations of time that impact the processing and assimilation of material on the parts of the students as well as the information that can be covered in a single semester.

A third limitation to this pedagogical strategy is that it does not address the complex dynamics related to the interplay of the instructor's cultural identity, the diversity or homogeneity of the student population, the institutional climate of the counselor education department and/or university or the sociopolitical issues of the surrounding communities. These factors invariably interact and have an effect on a counselor education program's overall effectiveness in attracting and retaining faculty members deeply invested in multicultural issues; in welcoming and supporting a diverse student body; and in producing counselors who are multiculturally competent.

\section{Conclusion}

Counselor educators need to continue developing and studying pedagogical strategies for teaching multicultural counseling. The desired end result of a culturally sensitive counselor who applies multicultural understanding to every counseling relationship requires careful planning. This article has presented one possible approach to the teaching of multicultural counseling based on careful planning and explicitly incorporating elements of the research base available on multicultural counselor education.

Given the currently popular structure of requiring one specific course on multicultural issues, it may be helpful for counselor education programs to frame it as a way to begin the process of developing multicultural counseling competency in students. If students can personally invest in cultural identity exploration through self-reflection, experience confronting cultural differences, and encounter the challenges of developing a helping relation with a cultural Other, they may be more likely to seek out opportunities to keep learning. Rather than the equipping students with a bag of counseling tricks for working with diverse clients, it may be more important to foster engagement in learning about diversity issues because they are inherently exciting and interesting. It is this commitment to a continuing journey that is the hallmark of culturally competent counselors and can best meet the spirit of the multicultural counseling competencies.

\section{References}

Arredondo, P., Toporek, R., Brown, S. P., Jones, J., Locke, D., Sanchez, J., \& Stadler, H. (1996). Operationalization of the multicultural counseling competencies. Journal of Multicultural Counseling $\mathcal{E}$ Development, 24, 42-78.

Atkinson, D. R., Morten, G., \& Sue, D. W. (1983). Counseling American Minorities: A cross-cultural perspective (2nd ed.) Dubuque, IA: William C. Brown.

Berg-Cross, L. \& Zopetti, L. (1991). Person-In-Culture interview. Journal of College Student Psychotherapy, 5(4), 5-21.

Bulkin, E. (1984). Identity: Skin blood heart. In Bulkin, E., Pratt, M. B., \& Smith, B. Yours in Struggle. New York: Long Haul Press.

Cross, W. E. (1991). Shades of Black: Diversity in African American identity. Philadelphia, PA: Temple University Press.

Hardy, K. \& Laszloffy, T. (1995). The cultural genogram: Key to training culturally competent family therapists. Journal of Marital and Family Therapy, 21(3), 27-37.

Helms, J. E. (1990). Black \& White racial identity: Theory, research, and practice. Westport, CT: Greenwood.

Holcomb-McCoy, C. C. \& Myers, J. E. (1999). Multicultural competence and counselor training: A national survey. Journal of Counseling $\mathcal{E}$ Development, 77(3), 294-302.

Kim, B. C. (1981). New urban immigrants: The Korean community in New York. Princeton, NJ: Princeton University Press.

Kiselica, M. S. (1998). Preparing Anglos for the challenges and joys of multiculturalism. The Counseling Psychologist, 26(1), 5-22.

Locke, D. C. (1990). A not so provincial view of multicultural counseling. Counselor Education $\mathcal{E}$ Supervision, 30(1), 18-25.

McIntosh, P. (1988). White privilege and male privilege: A personal account of coming to see correspondences through work in women's studies. In M. Andersen and P. H. Collins (Eds.) (1995). Race, class, and gender: An anthology. (2nd ed., pp. 76-87). Belmont, CA: Wadsworth.

Pedersen, P. (1994). A Handbook for developing multicultural awareness. Alexandria, VA: American Counseling Association.

Pinterits, E. J. \& Atkinson, D R. (1998). The diversity video forum: An adjunct to diversity sensitivity training in the classroom. Counselor Education \& Supervision, 37, 203-216.

Ponterotto, J. G., Rieger, B.P., Barrett, A., \& Sparks, R. (1994). Assessing multicultural counseling competence: A review of instrumentation. Journal of Counseling \& Development, 72, 316-322.

Ponterotto, J. G. (1988). Racial consciousness development among White counselor trainees: A stage model. Journal of Multicultural Counseling $\mathcal{E}$ Development, 16, 146-156.

Reynolds, A. L. (1995). Challenges and strategies for teaching multicultural counseling courses. In J. G. Ponterotto, J. M. Casas, L. A. Suzuki, \& C. M. Alexander (Eds.), Handbook of multicultural counseling. (pp. 312- 330). Thousand Oaks, CA: Sage.

Ridley, C. R. (1995). Overcoming unintentional racism in counseling and therapy: A practitioner's guide to intentional intervention. Thousand Oaks, CA: Sage.

Ridley, C. R., Espelage, D. L., \& Rubinstein, K. J. (1997). Course development in multicultural counseling. In D. B. Pope-Davis \& H. L. K. Coleman (Eds.) Multicultural counseling competencies: Assessment, education and training, and supervision (pp.131-158). Thousand Oaks, CA: Sage Publications.

Riggs, M. (Producer and director). (1995). Black is...black ain't: A personal journey through black identity. [Film]. (Available from Independent Television Service, California Newsreel, San Francisco, CA)

Ruiz, A. S. (1990). Ethnic identity: Crisis and resolution. Journal of Multicultural Counseling \& Development, 18, 29-40.

Sodowsky, G. R., Kuo-Jackson, P. Y., \& Loya, G. J. (1997). Outcome of training in the philosophy of assessment: multicultural counseling competencies. In D. B. Pope-Davis \& H. L. K. Coleman (Eds.) Multicultural counseling competencies: Assessment, education and training, and supervision (pp. 3-42). Thousand Oaks, CA: Sage Publications.

Sodowsky, G. R. (1996). The Multicultural Counseling Inventory: Psychometric properties and some uses in counseling training. In G. R. Sodowsky \& J. Impara (Eds.), Multicultural assessment in counseling and clinical psychology. Lincoln, NE: Buros Institute of Mental Measurements. 
Sue, D. W., Arredondo, P., \& McDavis, R. J. (1992). Multicultural counseling competencies and standards: A call to the profession. Journal of Multicultural Counseling \& Development, 20, 644-688.

Sue, S., Akutsu, P. D., \& Higashi, C. (1985). Training issues in conducting therapy with ethnic-minority-group clients. In P. Pedersen (Ed.), Handbook of cross-cultural counseling and therapy. (pp. 275-280). Westport, CT: Greenwood.

Sue, D. W., \& Sue, D. (1990). Counseling the culturally different: Theory and practice (2nd ed.). New York: John Wiley.

Sue, D. W., Bernier, J. E., Durran, A., Feinburg, L., Pedersen, P., Smith, E. J., \& Vasquez-Nuttall, E. (1982). Position paper: Cross-cultural counseling competencies. The Counseling Psychologist, 10, 45-52.
Sue, D. W., Carter, R. T., Casas, M. J., Fouad, N. A., Ivey, A. E., Jensen, M., LaFrombaise, T., Manese. J. E., Ponterotto, J. G., Vasquez-Nutall, E. (1998). Multicultural counseling competencies: Individual and organizational development. Thousand Oaks, CA: Sage.

Thompson, C. E. , Worthington, R., and Atkinson, D. R. (1994). Counselor content orientation, counselor race, and Black women's cultural mistrust and self-disclosures. Journal of Counseling Psychology, 41(2), 155-161.

Wah, L. M. (Producer and director). (1994). The Color of Fear. [Film]. (Available from Stirfry Productions, 3345 Grand Ave., \#3, Oakland, CA 94610).

\section{Appendix: Some documentary films on issues of identity and oppression}

A class divided. (1997). (Produced by W. Peters. Available from Yale University films for PBS-Frontline.)

The famous film of Jane Elliot's first grade class divided into blue eyes and brown eyes, demonstrating the rapidity with which children learned prejudice.

After Stonewall. (1999). (Produced by J. Scagliotti. Available from First Run Features, New York, NY).

Feature-length film that looks at events in the gay rights movement after the historic Stonewall incident.

Black is...black ain't: A personal journey through black identity. (1995). (Produced and directed by M. Riggs. Available from Independent Television Service, California Newsreel, San Francisco, CA)

An exploration of the meaning of Blackness, the role of religion in the African-American community, and the experience of sexism and homophobia through the personal odyssey of a African American gay man dying of AIDS.

Blacks and Jews. (1997). (Produced by Snotow-Kaufman. Available from California Newsreel, San Francisco, CA)

85-minute film examines the history of collaboration and conflict between the two groups, with an emphasis on New York City and Oakland, California.

Breaking the silence. (1995). (Produced by the Women's Feature Service. Available from Chip Taylor Communications, Derry, $\mathrm{NH})$

28-minute film covering human rights abuses against women.

Breaking the silence. (1984). (Produced by E. Mason. Available from Cinema Guild, New York, NY).

58-minute film on the impact of the Holocaust on survivors and later generations.

Crimes of hate. (1990). (Produced by the AntiDefamation League. Available from ADL Film Library, Hohokus, NJ).

A 30-minute overview of racist, anti-Semitic, homophobic hate crimes.

Homeless home movie. (1997). (Produced by P. Hennessey. Available from Media Visions, Minneapolis, MN).

84-minute documentary that follows the stories of six different homeless people over the course of a year.

In the white man's image. (1991). (Produced by PBS. Available from PBS Video, Alexandria, VA.

PBS special that looks at the history of the Carlisle boarding school and the policy of taking away Native American children from their families in an attempt to change their culture.

Means of Grace. (1996). (Produced by J. Clement. Available from New Day Films, Hohokus, NJ).

Documentary of a 1950's housewife and a internal evocation of insanity.
Mr. Nobody. (1991). (Produced by L. Wright. Available from: Filmmakers Library, New York, NY).

A 36-minute documentary that examines legal, ethical and human issues of the aged through the case study of a 65 year old man and his struggle to live independently.

Oaxacalifornia. (1994). (Produced by T. Ziff. Available from University of California Extension Center for Media. Berkeley, CA)

A 56-minute bilingual documentary of the life of a middle-class Mexican American family in Fresno, CA who return for a visit to their ancestral home in Mexico.

Race, the floating signifier. (1996). (Produced by S. Jhally. Available from Media Education Foundation, Northampton, MA)

A lecture by Stuart Hall on race and the meaning of social signifiers like skin color.

Racism in the news. (1992). (Produced by S. Maoda and S. Nakamura. Available from Media Action Research Center, Nashville, TN).

A short film analyzing news portrayals of people of color in particular ways.

Run of the sacred hoop. (1999). (Produced by A. Lukaszewski. Available from Paha Sapa Films).

33-minute documentary of a Lakota Nation members event that addresses the themes of acculturating youth , land seizure, and many other issues facing Native Americans today through a 500 mile run in the Black Hills.

Children of the camps. (1999). (Produced by I. Satsuki. Available from National Asian American Telecommunications Association, San Francisco, CA).

A 60-minute documentary that captures the experiences of six Japanese American children in the internment camps in the U.S. during WWII in group therapy.

Sexism in language. (1991). (Produced by Thames Color Production. Available from Films for the Humanities \& Sciences, Princeton, NJ) A short film demonstrating and analyzing the use of sexism in language.

Skin deep. (1995). (Produced by F. Reid. Available from Iris Films, Berkeley, CA)

Interviews with college students talking about race and racism.

The color of fear. (1994) (Produced by L. M. Wah. Available from Stirfry Productions, 3345 Grand Ave., \#3, Oakland, CA 94610). A 60-minute documentary that follows a diverse men's group confronting each other on issues of racism through a weekend.

When Billy broke his head and other tales of wonder. (1994). (Produced by B. Golfus. Available from Fanlight Productions, Boston, MA) An 60 minute documentary made by a man who experienced traumatic brain injury and went on a journey to investigate and document the struggle faced by people with disabilities. 